\title{
Televizyon ve Sosyal Medyanın Çocuklar Üzerindeki Etkileri ve Yapılması Gerekenler
}

\section{The Effects of Television and Social Media on Children and What We Need to Do}

\begin{abstract}
Sefa Bulut
Ibn Haldun Üniversitesi, Türkiye

sefabulut22@gmail.com

Geliş Tarihi: 23 Kasım $2020 \quad$ Kabul Tarihi: 15 Ocak $2021 \quad$ Yayın Tarihi: 28 Ocak 2021

Öz: Televizyon ve sosyal medya artık hayatımızın ayrıımaz bir parçası haline gelmiştir. Bu medya organlarının çok sayıda faydasının yanında zararları da bulunmaktadır. Bunlar en çok çocukları etkilemekte ve onları için zararlı sonuçlar oluşturmaktadır. Bunu ailelerin tek başına engellemesi mümkün değildir. O nedenle, okulların ve sağlık kuruluşlarının medya eğitimine önem vermesi ve bu konuda duyarlılık geliştirmesi önemlidir. Medyanın zararlı etkileri ancak ulusal düzeyde bir koruma ile önleme programı ve politikası olursa etkili olabilecektir. Buradan hareketle vatandaşların ve sivil toplum örgütlerinin ulusal düzeyde bir farkındalık oluşturarak, hükümetler üzerinde oluşturacağı baskı yoluyla politika değişimine gitmeleri sağlanmalıdır. Diğer yandan, televizyon kanalları, sosyal medya platformları ve eğlence endistürüsün tümü de sorumlu davranmaya teşvik edilmeli ve baskı yapılmalıdır. Bu, toplumsal düzeyde bir halk sağlığı sorunudur o nedenle toplumdaki herkesi ve toplumun her katmanını ilgilendiren bir sorun olarak ele alınmalıdır.
\end{abstract}

Anahtar Kelimeler: Sosyal Medya Kullanımı, Çocuklar ve Televizyon, Çocuklar ve Sosyal Medya, Sosyal Medyanın Yıkıcı Etkileri

Abstract: Television and social media become an inseparable part of our daily lives. Even though these media organs have many beneficial effects, there are also many harmful effects on children. They may influence children in a very negative way and have many harmful consequences. The families are illequipped to deal with this problem and only they can effectively deal with the issue. Therefore, it is important for schools and health institutions to put an emphasis on media education and develop public awareness about that. The harmful effects of the media can only be stopped if there is a national policy for prevention and protection from it. Hence, citizens and non-profit organizations can create a nationwide awareness, which by doing that they should be able to put pressure on the government and prompt a policy change. On the other hand, television channels and social media providers should be encouraged and pressured to behave responsibly. This constitutes a social and public health problem so that should be considered an interest of everyone and every segment of society.

ORC-ID: S. Bulut 0000-0002-2622-4390 
Keywords: Use of Social Media, Children and Television, Children and Social Media, Harmful Effects of Social Media Çocuk ve ergenlerin bilgisayar, cep telefonu, oyun konsolu, internet, sosyal medya kullanmaları ile televizyon seyretmeleri; bu tür elektronik iletişim araçlarının onlar üzerindeki etkilerini araştırmak üzere farklı alanlardaki bilim insanlarının dikkatini çekmiştir. Son yıllarda bu konulardaki araştırmalar, alanında uzmanlaşmış uyku, pediatri, psikiyatri, psikoloji, medya-iletişim, eğitim ve hukuk dergilerinde hızla yer edinmeye başlamıştır.

Insanlar artık geleneksel medyanın yanında cep telefonları, akıllı telefonlar ve iPadlerle sosyal medyayı takip etmektedir. Bu yeni medyaya "new media" denmektedir (Strasburger, Hogan, Mulligan, Ameenuddin, Christakis, Cross, \& Al, 2013).

Günümüzde medyanın çok güçlü bir dönüştürücü etkisi olduğu görülmektedir. Çocukların günde 2-3 saat televizyon seyretmeleri daha az fiziksel etkinlik, daha az okuma aynı zamanda arkadaşlarla daha az zaman geçirme ve etkileşimde bulunmak anlamına gelmektedir (Strasburger \& Donnerstein, 1999). Bu nedenle günümüz çocukları önceki kuşaklara göre bazı konularda dezavantajlı durumdadırlar.

Amerika'daki bir merkezin yaptığı araştırmaya göre, okul öncesi çocuklarının \% 25 'inin, ilkokul çocuklarının \%35'inin ve lise öğrencilerin \%50'sinin odasında TV seti olduğu bulunmuştur (Annenberg Public Policy Center, 1997).

Amerikan Pediatri Akademisi Klinik Raporunda (2011) sosyal medyanın çocuk, ergen ve aileler üzerindeki etkisi çok çarpıcı bir şekilde ortaya konulmuştur. Bu çalışmaya göre sosyal medya, çağımızda çocukların ve ailelerin ilgilendiği en yaygın aktivite aracıdır. Aile ve çocuklar bilgi alma, bir şey sorma, eğlenme ve sosyalleşme için en çok sosyal medyayı kullanmaktadırlar. Bunlar arasında sosyal medya siteleri (Facebook, MySpace, Twitter), sanal ortamlar (Club Penguin, Second Life, the Sims) ve video siteleri (YouTube, Bloglar) bulunmaktadır. Bu çalışmanın bulgularına göre, ergenlerin \%75'inin cep telefonu var ve $\% 25$ 'i sosyal medyayı aktif olarak kullanıyor. Ergenlerin yarısından fazlası günde bir defadan daha fazla sosyal medyaya giriyor. Hatta \%22'si günde 10 defadan fazla sosyal medyaya hesaplarına giriyor ve kontrol ediyor. Yine bu çalışmada ergenlerin \% 54'ünün mesajlaşmayı aktif olarak kullandıkları ve \%24'ünün de DM (direkt mesaj) kullandıkları bulunmuştur.

Çocuk ve ergenlerin kendilerini kontrol etme (self-regulation) yeteneğini ele aldığımızda örneğin sanal ortamda ne kadar zaman harcadıkları ve zamanın ne kadar hızlı geçtiği, 
nelerin kendileri için yararlı ve zararlı olduğunu tam olarak anlayamadıkları için risk altındadırlar. Çalışmalar gösteriyor ki, gerçek dünyada yaşanan sorunlar aynen online ortama da taşınmaktadır. Öyle ki; siber zorbalık, mahremiyetin ihlal edilmesi, sexting (mahrem içerikli resimlerin gönderilmesi), internet bağımlılığı ve uyku yoksunluğu sorunları sıkça karşımıza çıkmaktadır. Buna karşın, aileler tüm bu sorunlarla baş edebilmek için yeteri kadar eğitimli ve donanımlı değillerdir. Çalışmalar ailelerin çocuklarının online ortamlarda nasıl sosyalleştiğini bilmediklerini göstermektedir. Çünkü ailelerin bunları takip edecek teknik becerileri ve zamanları yoktur.

Ailelerin anlamakta zorluk çektiği diğer bir nokta ise, artık online ortamların çocukların off-line yaşantısının ayrılmaz bir parçası olduğudur. Özellikle de yaşadığımız Covid-19 sürecinde, dersler online ortama taşınmış ve çocuklar bir anlamda da daha fazla bilgisayar, akıllı cep telefonu ve sosyal medya kullanmak zorunda kalmışlardır. Salgın tehlikesi bittiğinde de çocukların sosyal medya kullanımlarının devam edeceği tahmin edilmektedir.

Sosyal medya kullanımı çocuk ve ergenlerin iletişim yeteneklerini geliştirebilir, yeni bağlantılar sağlayarak sosyalleşmelerine katkıda bulunabilir ve onların bilgisayar, akıllı telefon ve bazı başka teknik becerilerinin gelişmesini sağlayabilir (Livingstone, Haddon, \& Görzig, 2012). Bu nedenle, öyle görünüyor ki; günümüzdeki çocukların duygusal ve sosyal gelişiminin büyük bir bölümü internet ve akıllı telefon ortamında geçmektedir. Özellikle de yaşadığımız Covid-19 salgını nedeni ile çocuklar daha çok medya iletişim araçlarını kullanır hale gelmişlerdir. Bu durumun sonucunda dijital ortamlarda daha çok zaman geçirme, yalnızlıklarını giderme ve sosyalleşme fırsatları bulmuşlardır. Bu da hiç şüphesiz onların medya iletişim araçlarını daha fazla kullanmasına ve belki de bağımlılık derecesine gelen bir duruma yol açmıştır.

Çocuk ve ergenlerin uyku ve uyku düzenleri en çok araştırılan konular arasındadır. Uykunun öğrenme, hafıza ve duygu düzenlemesi davranışlarıyla ilgili olduğu bulunmuştur. Örneğin, uyku yetersizliği ve kalitesiz uykunun işlem yapan ve çalışan hafızaya olumsuz etkisi olduğu, konsantrasyon düşüklüğüne ve dolayısıyla da akademik başarıda düşüşe neden olduğu bulunmuştur (Cain \& Gradisor, 2010).

Diğer bir çalışmada da çocuk ve ergenlerin uyku sürelerinin önceki kuşaklara göre daha da azaldığı belirtilmiştir. Çocuklar babalarına ve dedelerine nazaran daha az uyuyor olmuşlardır (Dollman, Ridley, Olds, \& Lowe 2007). Bunun olası nedenleri ise elektriğin insan hayatına girmesi ve daha sonraki yıllarda da elektronik araçların her türlüsünün 
çokça kullanılmasıdır. Bunda da ebeveyn kontrolünün azalması ve elektronik medyanın çokça ve geç saatlere kadar kullanılmasının etkisi vardır (SBS Australia, 2009).

Amerika Birleşik Devletleri'ndeki Ulusal Uyku Vakfının (2006) araştırmasına göre ergenlerin \%97'nin yatak odasında mutlaka bir elektronik araç vardır. Bu çalışmada ergenlerin \%90'nın odasında music player, \%57'sinde televizyon, \%43'ünde oyun konsolu, \%42'sinde cep telefonu, \%34'ünde ev telefonu, \%28'inde bilgisayar ve \%21'ininde odasında internet bağlantısının olduğu belirtilmiştir. Bu çalışmaya göre, erkek ergenlerin odalarında daha çok TV ve bilgisayar olduğu bulunmuştur. Aynı çalışmaya göre, ilkokul çağındaki çocukların \%43'ünün odasında TV, \%20'sinde bilgisayar ya da oyun konsolu ve \%14'ünde ise cep telefonu bulunuyor. Bu araştırmanın sonuçları gösteriyor ki, yaş arttıkça çocuk ve ergenlerin elektronik iletişim araçları kullanım oranları artmaktadır.

A.B.D. Uyku Vakfının araştırmasına göre; odalarında 4'ten fazla elektronik araç olan ergenler, okul günlerinde de tatil günlerinde de daha az uyuyorlar. Yine bu çocukların okulda çok yorgun ve uykulu oldukları hatta derslerde ya da teneffüslerde uyudukları ve gün içerisinde de ayık kalabilmek için daha çok kafeinli içecekler içtikleri saptanmıştır.

Genellikle, yatarken televizyon seyretme alışkanlığı olan çocukların odalarında televizyon cihazlarının olduğu tespit edilmiştir. Yine benzer şekilde, yatak odasında akıllı telefon olması ve geç saatlerde mesajlaşılması uykuya dalma süresini uzatmaktadır. Bu nedenle, elektronik aletlerin yatak odasına sokulmaması ve akşam 9'dan sonra kullandırılmaması gerekiyor. Bunun sağlanması için de anne babanın ciddi bir ebeveynlik yapması, çocukların davranışlarını gözlemlemesi ve disiplinli bir yaşam modeli oluşturması gerekmektedir. Anne babanın da bunu yapabilmesi için öncelikle bunun farkına varması ve kendi yaşantısında da bunlara dikkat etmesi gerekmektedir. Çocukların en çok, en yakınında olan insanları rol modeli aldıkları ve ona göre davrandıkları bilinmektedir. $O$ nedenle anne babanın da sadece kendilerini değil, çocuklarını da disiplinli ve sorumlu olarak yetiştirme sorumluluğu vardır.

Çocuklarla yapılan çalışmalar, televizyon seyretme saatlerinin arttıkça, uykuya direncin arttığını göstermektedir. İki saatten fazla TV seyreden çocuklarda uykuya dalma kaygısı oluştuğu dolayısıyla uyuyamadıkları ve gece yataktan kalkarak yürüme davranışları gösterdikleri bulunmuştur. Çocuklar kendileri seyretmeseler bile, anne babaları ile beraber TV seyretmeleri ya da bulundukları ortamlarda TV seyredilmesi çocukları "pasif izleyici olma" konumuna sokmaktadır ve bundan olumsuz şekillerde etkilenmektedirler. 
Diğer yandan anne-babalarla yapılan çalışmalar da, anne babalar aşırı TV izlemenin çocuklarının uyku düzenini bozduğunu belirtmişlerdir.

Diğer çalışmalarda da, pek çok çocuk ve ergenin, uykuya yardımcı olsun diye (sleep aid) TV seyrettiği tespit edilmiştir. Owens, Maxim, McGuinn, Nobile, Msall, Alario (1999) yatarken TV seyretmenin, çocukların \%77'sinin günlük uyuma rutini olduğunu belirtmiştir. Oysaki elektronik medya kullanımı uyku kalitesini ve niceliğini etkiliyor. Çocukları fizyolojik olarak uyarıyor, rahatlamalarını ve gevşemelerini zorlaştırıyor. TV ve bilgisayarlardan çıkan parlak ışık ve radyasyon melatonin hormonunun salgılanmasına engel oluyor ve sirkadiyen uyku ritmini bozuyor.

Amerikan Pediatri Derneği (American Academy of Pediatrics, 1995), okul çağı çocuklarının gün içerisinde en çok 2 saat televizyon seyredebileceklerini belirtmiştir. Benzer şekilde Japonya'da Gaina ve ark. (2006) bilgisayar kullanımı ve elektronik oyunların da günde en çok 2 saatle sınırlandırılmasını tavsiye etmiştir. Araştırma sonuçları çocukların tüm televizyon ve medya kullanımının 2 saatle sınırlandırılmasını önermiştir.

Yapılan çalışmalar uyku düzeninde ve elektronik medya kullanımında kültürel farklılıklar olabileceğini göstermektedir. Örneğin, Amerika Birleşik Devletleri'nde çocuk ve ergenlerin en çok televizyon ve kablolu televizyon izledikleri, Japonya'da ise daha çok cep telefonu ile oynadıkları bulunmuştur (Oka, Suziki \& Inoue, 2008). Diğer yandan, Brezilya'da kızlar bilgisayarı daha çok kullanırken, Amerika'da erkeklerin daha çok bilgisayar kullandıkları bulunmuştur (Mesquita \& Reimao, 2007).

Davis (1992) Çocukları televizyonun zararlı etkilerinden korumak için onlara beş ilkeyi öğretmemizi tavsiye etmiştir. Bunlar; "Sen TV'de gördüklerinden daha akıllısın, TV dünyası gerçek değil, TV bazı insanların diğerlerinden daha değerli olduğunu öğretiyor, TV tekrar tekrar hep aynı şeyi yapıyor, Bazı kişiler bu yayınlardan, reklamlardan para kazanıyor" Bunları çocuklara öğretirsek ve çocuklarla beraber tartışırsak medyanın zararlı etkilerini içselleştirerek öğrenebilir ve bunlardan kendilerini koruyabilirler.

\section{Sosyal Medyanın Yararları}

Sosyal medyanın bazı yararlarından da bahsetmek gerekir. Sosyal medya gençlere sosyalleşme ve iletişim kurma imkânı vermektedir. Çocuklar ve gençler arkadaşları ve aile üyeleri ile ilişki kurabilirler, yeni arkadaşlar edinebilirler, resim ve fikir paylaşabilirler, toplumla sosyalleşebilirler, sivil toplum kuruluşlarıyla tanışabilir ve üye 
olabilirler. Ayrıca yaratıcılıklarını geliştirebilirler ve kendilerinden farklı olanları tanıyarak onlara karşı saygı ve tolerans geliştirme fırsatı bulabilirler. Bununla beraber, arkadaşları ile beraber ödev yapma, grup projelerine katılma, beyin fırtınası yapma ve bazı bloglarla siteleri kurmayı ve kullanmayı öğrenebilirler. Çocuklar, öğretmenlerine ve anne babasına sormaya çekinebilecekleri cinsel gelişim bilgilerini, stresle baş etmeyi, depresyonu tanımayı, benzer sorunları olan insanlarla iletişim kurarak bilgi alışverişinde bulunmayı güvenilir sağlık sitelerinden öğrenebilir. Beden ve ruh sağlığı ile ilgili bilgilere ulaşabilir (O'Keeffe \& Clarke-Pearson, 2011).

\section{Medyanın Çocuklar Üzerindeki Etkisi}

O'Keeffe ve Clarke-Pearson tarafından hazırlanan, Amerikan Pediatri Derneğinin Klinik Raporunda (2011), yaşları 8 ile 10 arasındaki çocukların toplamda 8 saat farklı medya platformlarında gezdikleri, hatta yaşı daha büyük olan çocukların 11 saatten daha fazla sosyal medyada zaman harcadıkları tespit edilmiştir. Öyle görünüyor ki, çocuklar okuldan çok sosyal medyada zaman geçirmektedirler.

Yine aynı raporda, çocuk ve ergenlerin \%71'nin yatak odalarında televizyonları olduğu ve 4 saatten fazla TV seyrettikleri, üçte birinin televizyonu başka platformlardan seyrettikleri, \% 84'ünün yüksek hızda internetleri olduğu, üçte birinin yatak odasında internetleri olduğu belirtilmiştir. Yine ergenlerin \%75'inin cep telefonu olduğu, \% 88'inin mesaj kullandığı, yarısının günlük 50 ya da daha fazla text mesaj gönderdiği ve üçte birinin de günlük 100'den fazla mesaj gönderdikleri, \%60'ından fazlasının da yatma saatinden sonra mesaj aldığı ve bunlara cevap yazdığı belirtilmiştir. Buna karşılık, çocuklar ailelerinin çoğunun çok az kuralı olduğunu ve çocukların üçte ikisi ise ailelerinin hiç kuralının olmadığını belirtmişlerdir.

Amerikan Pediatri Derneği raporunda, okulları, politikacıları, reklam ve eğlence sektörünü, çocuk ve ergenlerin medya karşısında korunması konusunda uyararak sorumlu davranılması gerektiğini vurgulamıştır. Aynı zamanda aileler, öğretmenler, çocuk doktorları medyanın zararlı yönlerine dikkat çekmeli ve uygun kullanımını desteklemelidir.

Yine doktor, psikiyatrist, pediatrist, psikolog, psikolojik danışman gibi profesyonelleri ve eğitim sendikaları eğlence endüstrisine baskı yapmalı, rehberlik etmeli, medyayı kötüye kullanmanın zararlarını anlatmalı, içeriği belirlemeli ve raporlar hazırlayarak kamuoyu oluşturmalıdır (O’Keeffe ve Clarke-Pearson, 2011). 


\section{Uzmanlara Tavsiyeler}

Her şeyden önce, çocuklarla beraber çalışan, öğretmen, psikolog, çocuk doktoru, özel eğitim ve spor öğretmeni gibi uzmanların medya ve medya kullanımı ile ilgili konularda genel bilgi sahibi olması gerekir. Örneğin; internet bağımlılığı, obezite, şiddet, uyuşturucu ve akran zorbalığı gibi konuların medya kullanımı ile ilgisini çok iyi anlamış olmaları gerekir. Aynı şekilde zaman içerisinde ortaya çıkan sosyal olayları iyi takip etmeleri, bunların çocuklar üzerindeki etkileri açısından duyarlı olmaları ve gerekli tedbirleri almaları gerekir.

Çocuklara sorulacak 2 önemli soru vardır, bunlardan birisi kaç saat televizyon seyrettikleri ve diğeri de odalarında televizyon olup olmadığıdır. Söyle ki, çocukların odasında TV olması obezite, madde kullanımı ve cinsel deneyimler yaşama riskini arttırmaktadır (Staiano, Harringston, Broyles \& Gupta, 2013).

Eğer çocuklarda saldırgan davranışlar, obezite şişmanlık, tütün, alkol, madde bağımlılığı ve okulda başarısızlık varsa daha ayrıntılı "media history" (medya kullanımı) araştırılmalıdır. Fakat diğer yandan, kendileri de çok televizyon seyreden profesyoneller ve çocuklarla çalışan uzmanlar bunu farketmeyebilir.

Amerikan Tıp Derneği (American Medical Association, 1996) doktorların çocuklarla görüşürken medya anamnezi almasını (medya kullanımı, media history) ve şu soruların sorulmasını önermiştir. "Bir günde kaç saat TV seyrediyorsun? Hangi diziyi ya da filmi seyredeceğine nasıl karar veriyorsun?, TV seti nerede? Hangi odada ya da odalarda var?

TV seyretmekle ilgili evinizde bir kural var mı? (ödevden sonra gibi), Favori TV dizi ve filmlerin neler? TV müzik ve oyunlarla ilgili kural var mı?, Seninle beraber kim TV seyrediyor? Seyrediyorlar mı ve Internette geziyor musun?" gibi soruların sorulmasını tavsiye etmiştir.

\section{Ailelere Tavsiyeler}

Hiç şüphesiz çocukları psikolojik ve sosyal olarak sağlıklı yetiştirmek ailenin en büyük görevidir. Çocukların yeme, içme, uyuma ve temizlik ihtiyaçları karşılanırken onların duygusal ve sosyal intiyaçları da unutulmamalıdır. Aile bireyleri bunlardan da sorumlu olmalı ve gerekli tedbirleri almalıdır. Ebeveynlerin görevlerinden biri de çocukları medyanın olumsuz etkisinden korumaktır. Günümüzde bu artık bir zorunluluk haline gelmiştir. O nedenle; ailelerin ekran karşısında geçirilen saati 1-2 saat arasında sınırlandırması, hatta 2 yaşından küçüklere hiç TV seyrettirilmemesi, cep telefonu yada 
oyun konsollarıyla oynattırılmaması, TV seti, bilgisayar gibi elektronik araçları yatak odasının dışında tutulması, çocukların gezdiği sayfaları kontrol edilmesi gerekmektedir. Çocukların yalnız değil, aile ile birlikte TV, film seyretmesi ve internet kullanımının beraber yapılması daha sonra bunu bunu bir tartışma ile bitirerek, öğretim yöntemi olarak kullanılması tavsiye edilmektedir. Ebeveynlerin aktif ebeveynlik yaparak, kesin "yemek saati", "yatma saati" ve "medya kullanım saati" planları yapması, cep telefonu kullanımı, mesaj gönderme, internet, sosyal medya kullanımı konularında mantıklı ve kesin kurallarının olması gerekmektedir.

\section{Ailenin Rolü}

Birçok aile çocuklarının medya kullanımını düzenli ve tutarlı olarak kontrol etmiyor ya da edemiyor. Bunun nedenlerinden birisi de ailelerin teknik bilgisinin çocuklardan daha az olması, o nedenle de bunun nasıl yapılacağını bilmemeleridir. Kendilerine, çocukların kaç saat sosyal medya kullandığı sorulduğunda, olduğundan daha az ifade ediyorlar. Yine aileler problemli programları seyretmediklerini söylüyorlar.

Buna karşın ailelerin yapması gereken, çocukları ile beraber televizyon seyretmektir. Bu en etkili yöntemlerden birisidir. Böylelikle programlar devam ederken bunlar hakkında çocuklarla konuşabilir ve onları gerekli gördükleri yerlerde uyarabilirler. Tüm uzmanların söylediği, medya kullanımının en fazla 1-2 saatle sınırlandırılması ve çocukların medya kullanımının kontrol edilmesidir (Strasburger \& Donnerstein, 1999).

Amerikan Pediatri Derneği, (American Academy of Pediatrics, 2010) özellikle evde ve okulda "medya eğitimi" (AAP, 2010) yapılmasını önermişstir.

\section{Okullar için Tavsiyeler}

Amerikan Pediatri Derneği (American Academy of Pediatrics) 2013 yılındaki "Çocuk, Ergen ve Medya" başlıklı bildirisinde, okullar için de bazı tavsiyelerde bulunmuştur. Bunlar söyle sıralanabilir. Ekip çalışması ve işbirliği yapılarak (okul-öğretmen-veli) veliler eğitilmeli, okulların tavsiye ettiği önerilere veliler evde uyarak bir tutarlılık sağlanmalıdır. Okul sahiplerinin, mütevelli heyetlerinin ve okul yöneticilerinin medyanın yıkıcı etkileri hakkında eğitilmesi; medya eğitiminin herkesi kapsayacak şekilde yaygınlaştırılması; dersler ve ödevler verilirken yenilikçi ve yararlı medya kullanımını teşvik edilmesi; öğretmen veli okul-aile birliği aracılığı ile aile rehberliğini arttırılması; yaşa uygun programların belirlenerek velilerle paylaşılması; öğrencilerin gereksiz ve zararlı web sayfalarına girmelerinin engellenmesi gibi konularda okullar öncülük ve liderlik edebilirler. 
Amerikan Pediatri Derneği (2013) hükümet düzeyinde alınabilecek önlemleri de sıralamıştır. Ulusal düzeyde raporlar hazırlanmalı, yıllara göre boylamsal araştırma yapılmalıdır. Eğlence endüstrisi ve reklam endüstrisini eğitmeli, baskı yapmalı daha çok sorumlu davranmaya teşvik etmelidir. Çocukların yaşları çok küçük olduğu için, kendini kontrol etme (self-regulation) çocuklarda çok işe yaramamakta bu nedenle abur cubur, fast food gibi gibi beslenmeye ilişkin konularda kural ve yasaklar olmalıdır. Devlet tarafından devam eden araştırma projeleri geliştirilmeli ve bunlar düzenli bir şekilde desteklemelidir. Zararlı madde ve yiyeceklerin televizyonda reklamının yapılmasının yasaklanması da önem arz etmektedir. Milli Eğitim Bakanlığının katkılarıyla çocuk ve ergenler için "medya eğitimi” programları hazırlanması gibi konularda devlet çalışma yaprak gençleri koruma amaçlı politikalar oluşturmalı ve uygulamalıdır.

\section{Okulların Görevi}

Okulların görevlerinden ilki, yine okul temelli medya eğitim programları hazırlanması ve bunların okullarda uygulanmasıdır. Örneğin, Avustralya'da anaokulundan liseye kadar (K12) medya eğitimi zorunludur. Benzer şekilde Kanada'da da ortaokul ve liselerde medya eğitimi zorunlu ders olarak okutulmaktadır. (Strasburger \& Donnerstein, 1999). Ülkemizde de medya eğitimi dersleri seçmeli olarak sunulmaktadır. Fakat çoğunlukla ya derse uzman öğretmen girmemekte ya da öğretmen yokluğundan bu dersler yapılmamaktadır. Aslında, özellikle günümüzde medya eğitiminin önemi her geçen gün daha çok artmaktadır. O nedenle bu dersin zorunlu bir ders olarak ilkokuldan liseye kadar her eğitim kademesinde en az bir kez verilmesi çok yararlı olacak ve çocuklarda medya okuryazarlığının gelişmesine katkıda bulunacaktır.

\section{Çözüm Önerileri}

Çözüm önerileri öncelikle birbirine paralel olmak üzere, kapsamlı olarak toplumun genelini de içine alacak şekilde sürdürülmelidir.

Öncelikle ailenin görevi, kendi çocuklarını takip etmek, kontrol etmek ve eğitmektir. Okullarda öğretmenler ve rehber öğretmenler, okul psikolojik danışmanları çocukları değerlendirirken televizyon ve medya ile olan ilişkilerini de sorgulamalı ve onları bu konuda eğitmelidir. Diğer yandan bu bir halk sağlığı sorunu olarak görülmeli ve aile hekimleri, doktorlar, psikiyatristler ve pediatristler doğrudan onları ilgilendirmese bile çocuk hastalarına medyayı ne kadar kullandıklarını sormalı ve onlara uygun tavsiyelerde bulunmalı ve çocuklar ve aileler için bilgilendirici broşürler vermelidir. 
Hükümetin görevi ise kanun, yönetmelik ve diğer düzenlemeleri yaparak üst düzeyde bir kontrol mekanizması geliştirmek ve sorunları birinci düzeyde koruyucu ve önleyici olarak engellemektir. Eğlence sektörü ve eğlence endüstrisinin görevi ise daha sorumlu davranarak, ucuz hesaplar ve kısa dönemli kazançlardan kaçınmak ve gençlerimizi uzun vadede her türlü zararlı etkilerden korumaktır.

Belirtilen nedenlerden ötürü, çocukları televizyon ve sosyal medyanın zararlı etkilerinden korumak sadece ailenin görevi değildir. Zaten aile bu savaşta tek başına yeterli olamamaktadır. Aileyi destekleyecek okul, sağlık ve eğitim kuruluşları devreye girmeli sonrasında hükümete ve eğlence sektörüne, televizyon kanallarına gerekli baskıyı yapmalıdır (Strasburger \& Donnerstein, 1999).

\section{Genel Olarak Yapması Gerekenler}

Toplum sağlığı merkezlerinde ekip çalışması yapılarak çocukların televizyon seyretme saatlerini, çocuklar için yararlı olan programları belirlemek ve uygun sürelerde televizyon seyretmeyi teşvik etmek.

Küçük broşür ve bilgilendirme formları hazırlayarak ailelere ve çocuklara vermek ve onlarda bu konu hakkında duyarlılık oluşturmak.

Özellikle aile hekimlerinin, doktorların ve hemşirelerin bu konuda okullarda ve kamu kuruluşlarında bilgilendirici seminerler yapması.

Aileleri sağlıklı medya kullanımı ve çocukları denetleme konularında eğitmek. Bu konuda duyarlılık oluşturmak için bilboardlara, panolara, otobüslere ve televizyonlara kamu spotu hazırlamak ve bunları her yerde yaymak.

Daha sağlıklı medya için lobi yapmak ve bu konuda duyarlılık geliştirmek. Belli platformlar oluşturarak, kamuoyunun ilgisini çekmek ve politika yapıcılara baskı yapmak.

Çocukları tedavi eden doktorların "agresif davranışlar ve okul başarısızlığı" olan çocuklar için "medya kullanım hikayesi-medya anamnezi” almasını teşvik etmek..

Medya eğitiminin ve medya okuryazarlığının okullarda zorunlu ders olması için Milli Eğitim Bakanlığının harekete geçirilmesi. 
Yerel ve ulusal TV kanalları ile iletişime geçerek yayın politikaları hakkında bilgilendirmeye ve caydırıcı olmaya çalışmak. Televizyon programlarında bu konuların tartışımasını sağlamak ve daha çok kişiye ulaşmaya çalışmak.

Okul aile birlikleri ile beraber çalışmak, bu konuda okulun ihtiyaçlarını tespit etmek ve okul aile birliği aracılığı ile velileri eğitmek ve bu konuda toplumsal duyarlılık kazandırmak.

Genel olarak ülke düzeyinde, Türkiye Büyük Millet Meclisi, Türk Psikiyatri Derneği, Türk Psikologlar Derneği, Türk Psikolojik Danışmanlık ve Rehberlik Derneği, Radyo Televizyon Üst Kurulu ve Milli Eğitim Bakanlığına yazı ve raporlar hazırlayarak farkındalık geliştirmek ve karar alıcılara baskı yapmaya çalışmak, en etkili yöntemlerden biridir.

\section{Teşekkür}

Bu yazıyı okuyarak düzeltmeler yapan Rehberlik ve Psikolojik Danışmanlık yüksek lisans öğrencisi Abdullah Aktaş’a katkılarından dolayı teşekkür ederim.

\section{Kaynakça}

American Academy of Pediatrics (2010). Council on Communications and Media. Policy Statement: Children, adolescents, substance abuse, and the media. Pediatrics, 126(4), 791-799.

American Academy of Pediatrics (2013). Policy Statement. Children, adolescents, and Media. American Academy of Pediatrics, 132(5), 958-961.

Annenberg Public Policy Center (1997). Television in the home: The 1997 Survey of Parents and Children. Philadelphia, PA: Annenberg Public Policy Center.

Cain, N. \& Gradisor, M. (2010). Electronic media use and sleep in school-aged children and adolescents: A review. Sleep Medicine, 17(8),735-742. doi: 10.1016/j.sleep.2010.02.006

Dollman, J., Ridley, K., Olds, T. \& Lowe, E. (2007). Trends in the duration of school-day sleep among 10-to 15-year-old South Australians between 1985 and 2004. Acta Paediatrica, 96, 1011-1014. DOI:10.1111/j.1651-2227.2007.00278.x

Davis, J. (1992). Five important ideas to teach your children about TV. Media and Values, 59/60, 10-14.

Gaina, A. et al. (2006) Morning-evening preference: Sleep pattern spectrum and lifestyle habits among Japanese junior high school pupils. Chronobiology International, 23(3), 607-621. dol: $10.1080 / 07420520600650646$

Livingstone, S., Haddon, L. \& Görzig, A. (2012). Children, risk and safety on the internet: research and policy challenges in comparative perspective. Policy Press, Bristol.

Madden, M. (2012). Privacy management on social media sites. Pew Research Center.

Mesquita, G. \& Reimao, R. (2007). Nightly use of computer by adolescents: its effects on quality of sleep. Arq. Neuropsiquatr, 65, 428-432. 
Oka,Y., Suziki, S. \& Inoue, Y. (2008).Bedtime activities, sleep environment, and sleep/wake patterns of Japanese elementary school children. Behavioral Sleep Medicine, 6, 220-233.

O'Keeffe, G. S. \& Clarke-Pearson, K. (2011). Clinical Report-The Impact of social media on children, adolescents, and families. American Academy of Pediatrics, 127 (4), 800-804.

Owens, J., Maxim, R., McGuinn, M., Nobile, C., Msall, M., \& Alario, A. (1999). Televisionviewing habits and sleep disturbance in school children. Pediatrics 1999, 104, e27.

SBS Australia (2009). Sleep Insight, 28 April 2009

Strasburger, V. C. \& Donnerstein, E. (1999). Children, adolescents, and the media and solutions. Pediatrics, 103(1), 129-139.

Staiano, A.E., Harringston, D. M., Broyles, S. T., Gupta, A., \& Katzmarzyk, P. T. (2013). Television, adiposity, and cardiometabolic risk in children and adolescents. American Journal of Preventive Medicine, 44(1), 40-47.

Strasburger, V., Hogan, D., Mulligan, D., Ameenuddin, N., Christakis, D., Cross, C., \& Al., E. (2013). Children, adolescents, and the media. Pediatrics, 132(5), 958-961. doi: 10.1542 /peds.2013-2656 